\title{
Sex differences on the contextual factors and physical activity levels among the Nigerian people during the COVID-19
}

\author{
Oladotun Sunday Adeyemo ${ }^{1^{\star}}$, Nurudeen Afolabi Sofoluwe ${ }^{2}$, Yinusa Olumuyiwa Ganiyu ${ }^{3}$, Odusanya \\ Abidemi lbrahim ${ }^{4}$, Oyelami, Lukman Oyeyinka ${ }^{5}$
}

\begin{abstract}
Background: In the context of flattening the curve of the spread of coronavirus in Nigeria, some factors were considered. This study aimed to investigate the relationship between some of the considered factors and physical activity and investigate sex differences on physical activity during the coronavirus pandemic in Nigeria.

Methods: The study was cross-sectional using an online survey and recruited participants from Nigeria's southwest geopolitical zone through the snowball sampling technique. Descriptive statistics (such as percentages), correlation analyses, and t-test of independent measures were used to analyze the data collected. The data collection was conducted from April to June 2020.

Results: The participants' age ranges from 18 to 73years, with a mean age of 42.9 years, a median of $43 y e a r s$, and a standard deviation of 5.41. The result showed a significant difference between males and females $(x=1001.21$; $\mathrm{SD}=1371.83$ ) on moderate physical activity during the pandemic in Nigeria. However, there was no significant relationship between contextual factors; perception of the spread $[r(467)=0.028 ; P>0.05]$, fear of contracting COVID$19[r(467)=0.041 ; P>0.05]$, stay at home measures $[r(467)=-0.030 ; P>0.05]$, sensitizing others about COVID-19 [ $r$ $(467)=-0.044 ; P>0.05]$, compliance with safety rules and regulations $[r(467)=0.052 ; P>0.05]$ and overall physical activity.
\end{abstract}

Conclusion: The study concluded that the relationship between contextual variables and physical activity among Nigerian people during the COVID-19 pandemic is not significant. Secondly, males and females are not different on vigorous and walking physical activity levels.

Keywords: COVID-19, Physical Activity, Contextual Measures, Sex Differences, Coronavirus, Nigeria

\section{Background}

The word pandemic is used to describe a disease that can affect people all over the world. Such disease should be novel, have the ability to spread in an unanticipated manner across boundaries of the world, severe enough to cause high mortality, have high rate of transmission, and must be communicable [1]. Humankind has at different times experienced diseases with the highlighted characteristics; however, the one the whole world is grappling with now is a coronavirus, also known as COVID-19. Coronavirus is a novel single strand of ribonucleic acid (RNA) viruses caused by Severe Acute Respiratory Syndrome Coroanavirus-2 (SARS-COV-2) with pneumonia-like symptoms. With the index case in Wuhan China by the end of

*Correspondence: os.adeyemo@oouagoiwoye.edu.ng

${ }^{1}$ Department of Psychology, Faculty of Social Sciences, Olabisi Onabanjo University, Ago-Iwoye, Nigeria

Full list of author information is available at the end of the article the year 2019, the number of cases worldwide is in astronomical proportion. Like 2003 SARS, coronavirus has affinity for respiratory organs, and it is more contagious because there is no immunity against the virus yet [2]. As the whole world is feeling the impacts of this disease, Africa could be having a triple tragic impact of the pandemic on her health, economy, and political systems [3].

In the context of stemming the spread of the virus, different countries of the world prescribed various public health measures in order to flatten the curve of the spread of the virus. Some of these contextual measures in Nigeria included full or partial national lockdowns of some cities, travel bans, social distancing, constant hand washing with alcohol-based sanitizers, coughing into the elbow, compulsory wearing of face masks in public places, washing of hands with soap, and water among other approaches. Specifically, lockdowns, travel restrictions, and social distancing strategies in some Nigerian states during the early periods of the pandemic were total, while others relaxed the measures for people to go out after a while 
[4]. These prescriptions have been revealed to have an inadvertent iatrogenic effect on people as they could likely lead to a lower level of engagement in any level of physical activity [5-7]. In turn, they could affect immunity, making it challenging to suppress some lifestyle illnesses such as diabetes, high blood pressure, which could be risk factors of or worsen the condition of COVID-19 illness [8]. Ordinarily, physical activity levels reflect the intensity of energy an individual burns through either engaging in walking, doing moderate physical activity, or engaging in vigorous physical activity. Interestingly, engaging in some physical activity parameters (walking, transportation to work, etc.) has an additive effect on physical activity [9].

The contextual variables containing the spread of COVID-19 considered in this study are public health measures, perception of the spread of COVID-19, fear of COVID-19, stay at home order, sensitizing others, and compliance measures. All these measures are believed to aid the control of the spread of coronavirus [10]. Expectedly, these measures are instituted to target minimal movements of humans, suggesting that the fewer people move around, the less the spread of the disease.

To a large extent, people in Low and Middle-Income Countries (LMICs) such as Nigerians are physically active mainly through transportations to their jobs and other places [11]. Unfortunately, the contextual control measures of COVID-19 make this impossible. As it was reported the fear of contracting COVID-19 was very high among those experiencing lockdowns $[12,13]$ explained that exercising may induce the fear of contracting the virus, thereby causing physical inactivity. While assertion may be logical [13], there are places where people still engage in outdoor physical activity [14]. We hypothesized that contextual factors would have a significant relationship with physical activity during the lockdown period resulting from Nigeria's coronavirus pandemic.

Less has been done as regards gender issues during COVID19 [15]. This is shown in the number of commentaries that have been written about the effects of measures to contain the pandemic on physical activity, with little attention given to differences among males and females on physical activity levels. We found few studies which looked into gendered implications of lockdowns on physical activity during COVID19 among adolescents in Croatia [16, 17] and Sicilian adults [18]. Sekulic et al. [17] found out that girls engaged more in overall physical activity than boys. The lockdown measures nearly made boys engage less in vigorous physical activities which typically found in gyms and clubs; however, such places are banned during the pandemic. Other studies conducted by Karuc et al. [16] and Giustino et al. [18] revealed that males tended to be more involved in physical activity than females. From the foregoing, we hypothesized that there would be a significant difference between males and females on each physical activity level during the lockdown measures occasioned by covid-19 in Nigeria.

This study would aid in providing sex-disaggregated evidence on physical activity level during the COVID-19 pandemic. It would also help in policy directions on tailor-made public health information on physical activity during the pandemic. This study would also fill the data gap regarding physical activity during the pandemic in Nigeria. Moreover, we could not find any previous study looking into this construct in Nigeria.

\section{Methods}

Online responses are elicited from a set of people who experienced lockdown caused by the COVID-19 pandemic in Southwest Nigeria. Southwest Nigeria is one of the leading geopolitical zones mostly ravaged by the pandemic in the country. The questionnaires were distributed via popular social media in Nigeria through the online cross-sectional survey, including WhatsApp media tool and Facebook. A total of 565 responses were received from the respondents in the study area. Out of the total responses received, 467 were found useful, representing $82.65 \%$ of the participants. The participants' responses were elicited some weeks after the National and the southwest state governments' initial lockdown, which started March 30th, 2020. The chosen area of study was then the epicenter of the coronavirus pandemic in the country. Lagos, a state in Nigeria's study region and former capital, currently tops the chart with $59.97 \%$ of confirmed cases as of April 19th, 2020, and even now. Information on health-related physical activities was collected in addition to perception and reactions to COVID-19 pandemic control strategies advocated by both national and state governments. The survey covered information on walking, moderate and vigorous physical activity levels carried out by the respondents, as well as time spent (number of minutes per day) on each activity in the past 7-days of stay at home. Data collection was conducted between April to June 2020.

The Snowball sampling technique was used to collect the data. The participants received the questionnaire as a google form on their WhatsApp groups or Facebook messenger groups and were encouraged to send it to other groups they belonged to, thereby recruiting participants who share some characteristics with them. Questions on the survey were guided by International Physical Activity Questionnaire (IPAQ) and scoring protocol. This study used IPAQ short form, which has been previously used in Nigeria $[19,20]$. The participants' level of activities (walking, moderate and vigorous) was assessed in the number of hours and minutes they engaged in the three activities per day and then in the last seven days. The scoring protocol for IPAQ can be found in (www.ipaq.ki.se).

\section{Statistical analysis}

Descriptive statistics (such as percentages), correlation analyses, and t-test of independent measures were used to analyze the data collected.

\section{Results}

The participants' age ranges from 18 to 73 years. The overall mean age of respondents is $42.82 \pm 9.60$ years. The percentage age distribution between 30 and 50 years is $65.1 \% ; 32.2 \%$ are between 31 and 40 years, while $32.9 \%$ are between 41 and 50 . A lower percentage $(24.2 \%)$ of respondents lies between 51 and 60 years. About $10.1 \%$ of the sample is less than 30 years, while $0.7 \%$ is older than 60 years. The sample is dominated mainly by the male $(72.6 \%)$ and $27.4 \%$ of the female. The majority (75.4\%) were married, with single constituting 23.1 percent of the sample (Table 1).

Involvement in different types of physical activity varies among the respondents. A higher percentage (69.6\%) of the sample did not participate in vigorous physical activity such as heavy lifting, aerobics, and fast bicycling, while $30.4 \%$ reported 
their involvement in vigorous physical activity. On the contrary, a larger percentage $(61.2 \%)$ of respondents reported moderate physical activity, while $38.8 \%$ did not indicate their involvement in a moderate activity such as playing table tennis, bicycling at a regular pace, and carrying light loads.

Table 1 Socio-demographic characteristics and involvement in vigorous and moderate physical activity

\begin{tabular}{lll}
\hline Variable & Description & $\%$ \\
\hline Age (Years) & $<30$ & 10.1 \\
& $31-40$ & 32.2 \\
& $41-50$ & 32.9 \\
& $51-60$ & 24.2 \\
Mean & $>60$ & 0.7 \\
Std. Deviation & 42.82 & \\
Gender & 9.60 & \\
& Male & 72.6 \\
Marital & Female & 27.4 \\
& Single & 23.1 \\
& Married & 75.4 \\
Physical activity & Separated & 0.9 \\
Vigorous activity & Widowed/Widower & 0.6 \\
& & \\
Moderate activity & Yes & 30.4 \\
& No & 69.6 \\
\hline
\end{tabular}

From table 2 above, it was shown that participants' perception of the spread of COVID-19 [r $(467)=-0.215 ; \quad P<0.01]$ significantly has a negative relationship with fear of COVID19. This simply means that the lower the perceptions of the spread of COVID-19, the more the fear of contracting COVID19. Also, participants' perceptions of COVID-19 [r (467) $=0.121 ; P<0.01]$ significantly have a positive relationship with staying at home. This means that the more the participants positively perceive COVID-19, the more they intend to stay at home. Less participation in sensitization to others about COVID-19 has a negative correlation with perceptions of the spread of COVID-19 [r (467) $=-0.122 ; P<0.01]$. However, stay at home measures $[\mathrm{r}(467)=0.160 ; P<0.01]$ significantly have a positive relationship with sensitization about COVID-19 to others; this means that the more participants obey the restriction order to stay at home, the more they get to sensitize others about COVID-19.

Furthermore, the more participants' fear of contracting COVID-19 [r $(467)=0.104 ; P<0.01]$, the more their level of compliance to safety rules. This suggests that fear of contracting COVID-19 significantly has a positive relationship with compliance to COVID-19 safety rules and regulation. However, stay at home order $[\mathrm{r}(467)=-0.128 ; P<0.01]$ significantly has a negative correlation with compliance with safety rules and regulation. That is, the more people stay at home, the less they comply with COVID-19 safety rules and regulations. More so, participation in sensitizing others about COVID-19 [r (467) =0.233; $P<0.01]$ is negatively associated with compliance with safety rules. The more participants sensitize the public and relatives about COVID-19, the less their compliance with safety rules. However, perception of the spread $[\mathrm{r}(467)=0.028$; $P>0.05]$, fear of contracting COVID-19 [r (467) $=0.041$; $P>=0.05]$, stay at home measures $[\mathrm{r}(467)=-0.030 ; P>0.05]$, sensitizing others about covid-19 [r (467) $=0-.044 ; P>0.05]$, compliance with safety rules and regulations $[\mathrm{r}(467)=0.052$; $\mathrm{P}>0.05$ ] did not have any significant relationship with participants' overall Physical Activity. This means that the hypothesis is not accepted.

The results in Table 3 showed that sex $(\mathrm{t}(465)=0.62$, $P>0.05)$ has no significant difference on vigorous physical activity, as male participants $\left(\mathrm{x}^{-}=1744.25 ; \mathrm{SD}=3063.75\right)$ are not significantly different from the female participants ( $\mathrm{x}^{-}=$ 1548.75; $\mathrm{SD}=2846.99)$.

However, sex (t $(465)=-1.84, P<0.05)$ is significantly different on moderate physical activity. Specifically, female participants $\left(x^{-}=1001.21 ; \quad \mathrm{SD}=1371.83\right)$ are significantly different from the male participants $\left(\mathrm{x}^{-}=768.14 ; \mathrm{SD}=1153.28\right)$. This simply implies that female participants were significantly involved in moderate physical activity than male participants. Moreover, sex $(\mathrm{t}(465)=0.39, P>0.05)$ has no significant difference on walking physical activity, as male participants $\left(x^{-}=307.18 ; \mathrm{SD}=605.76\right)$ did not significantly different from the female participants $\left(\mathrm{x}^{-}=218.35\right.$; $\left.\mathrm{SD}=671.62\right)$.

\section{Discussion}

Plato (427-347) asserted that lack of activity destroys human beings' good condition, while movement and methodical physical exercise save it and preserve it. This unarguably pinpoints physical activity's relevance in maintaining good well-being right from a very long time ago. Our study investigated this assertion in the context of lockdown and similar orders by the Nigerian government occasioned by coronavirus disease. Our study provides insight into the physical activity levels of individuals during the period of lockdown. The study also provides sex differences results of different physical activity levels during the coronavirus pandemic in Nigeria.

Projections from other studies were that coronavirus containment measures would significantly reduce participation in physical activity [5,7]. However, our study's result contradicted this assertion. This probably points to differences in the characteristics of our participants as different from other studies. We measured our participants based on their physical activity some weeks after the lockdown measures were instituted without recourse to their physical activity levels before lockdown. Simultaneously, others $[16,17]$ investigated the pre-lockdown physical activity to have a baseline score. It was shown from our results that more participants engage in moderate physical activity than vigorous physical activity.

Furthermore, based on the cumulative nature [9] of physical activity, it could mean that our participants engage in domestic physical activities that accumulate over time to be moderate physical activity levels rather than involving in structured vigorous-intensity physical activity. Likewise, as pointed out by [4], people still move around despite the public health efforts to contain the pandemic. Future studies can investigate the influence of socio-cultural factors on physical activity during the COVID-19 pandemic in Nigeria. 
Table 2 Summary of correlation analysis showing the association among contextual factors (public health measures, perception of the spread of Covid-19, fear of Covid-19, stay at home, sensitizing and compliance), and walking, moderate, vigorous, and overall Physical Activity for MET minutes for a week (7days).

\begin{tabular}{|c|c|c|c|c|c|c|c|c|c|c|c|}
\hline Variables & 1 & 2 & 3 & 4 & 5 & 6 & 7 & 8 & 9 & $\bar{x}$ & SD \\
\hline 1. Perception of the spread & 1 & & & & & & & & & 2.93 & 1.76 \\
\hline 2. Fear of Covid 19 & $-0.215^{* *}$ & 1 & & & & & & & & 5.92 & 1.64 \\
\hline 3. Stay at Home & $0.121^{* *}$ & -0.085 & 1 & & & & & & & 1.04 & 0.19 \\
\hline 4. Sensitizing & 0.031 & $-0.122^{* *}$ & $0.160^{* *}$ & 1 & & & & & & 1.05 & 0.22 \\
\hline 5. Compliance & -0.047 & $0.104^{*}$ & $-0.128^{* *}$ & $-0.233^{* *}$ & 1 & & & & & 4.27 & 0.95 \\
\hline 6. Walking Physical Activity & 0.004 & 0.040 & -0.040 & -0.053 & 0.034 & 1 & & & & 1690.67 & 3004.15 \\
\hline 7. Moderate Physical Activity & 0.034 & 0.048 & -0.03 & -0.008 & 0.083 & $0.390^{* *}$ & 1 & & & 832.03 & 1220.02 \\
\hline 8. Vigorous Physical Activity & 0.081 & -0.043 & 0.037 & 0.006 & -0.02 & -0.043 & -0.038 & 1 & & 300.10 & 623.88 \\
\hline $\begin{array}{l}\text { 9. Overall MET Minutes for Physical } \\
\text { Activity }\end{array}$ & 0.028 & 0.041 & -0.030 & -0.044 & 0.052 & $0.938^{* *}$ & $0.644^{* *}$ & $0.122^{* *}$ & 1 & 2822.80 & 3680.06 \\
\hline
\end{tabular}

Table 3 Summary of t-test of independent samples showing sex differences on Walking, Moderate and Vigorous Physical Activities

\begin{tabular}{|c|c|c|c|c|c|c|c|c|}
\hline Dependent Variable & Gender & $\mathbf{N}$ & $\bar{x}$ & SD & Df & $\mathbf{T}$ & $\mathbf{F}$ & $\mathbf{P}$ \\
\hline \multirow{3}{*}{ 1. VPA } & Male & 339 & 1744.25 & 3063.75 & & & & \\
\hline & & & & & 465 & 0.62 & 0.96 & $>0.05$ \\
\hline & Female & 128 & 1548.75 & 2846.99 & & & & \\
\hline & Male & 339 & 768.14 & 1153.28 & & & & \\
\hline MPA & & & & & 465 & -1.84 & 6.76 & $<0.05$ \\
\hline & Female & 128 & 1001.21 & 1371.83 & & & & \\
\hline \multirow{3}{*}{ WPA } & Male & 339 & 307.18 & 605.76 & & & & \\
\hline & & & & & 465 & 0.39 & 0.01 & $>0.05$ \\
\hline & Female & 128 & 281.35 & 671.62 & & & & \\
\hline
\end{tabular}

Dependent Variables: 1. Vigorous Physical Activity (VPA), 2. Moderate Physical Activity (MPA), 3. Walking Physical Activity (WPA)

There was no sex difference in physical activity engagement in our study's results, especially as we showed that both males and females are similar in walking and vigorous physical activity levels. Our findings disagree with the results from Croatia [17] and Sicilia [18]. Another finding from our study revealed that females engage more in moderate physical activity than males. This is a surprising result as an earlier study [16] revealed that there was a significant dip in moderate-vigorous physical activity for males more than females.

There are some noticeable differences in the participants of some of these studies to ours. Karuc et al. [16], and Sekulic et al. [17] used secondary school-age students and defined physical activity levels using School Health Action, Planning, and Evaluation System (SHAPES) and physical activity questionnaires. In contrast, we recruited participants in 18-70 years and operationalized physical activity using International Physical Activity Questionnaire (IPAQ). These two studies measured physical activity levels pre-pandemic and during the pandemic, while the present study only asked participants about their physical activity levels during the experience of the measures to contain the spread of coronavirus. Other studies could retrospectively determine the reasons for these gendered results in physical activity levels during this pandemic in Nigeria.

One major strength of this study is the online-based data collection method, which gave the study a geographical spread advantage as we effectively covered the southwest states where coronavirus was the worst hit. This also ensured we complied with the Presidential Task Force's restriction orders on the
COVID-19 pandemic in Nigeria. The self-report questionnaires used in this study could inadvertently contribute to limitation as participants might be biased in answering the questionnaires' items. Another limitation that other researchers should be aware of is that of generalizability. The study's participants are limited to Nigeria's southwest geopolitical zone, and the result should be interpreted in that context.

\section{Conclusion}

From our results, we can conclude that the relationship between contextual variables and physical activity among Nigerians during the COVID-19 pandemic is insignificant. Secondly, males and females are not different on vigorous and walking physical activity levels, while there was more female participation in moderate physical activity than males during COVID-19 lockdown measures.

\section{Abbreviation}

COVID-19: Coronavirus, SARS-COV-2: Severe Acute Respiratory Syndrome Coroanavirus-2, SHAPES: School Health Action, Planning, and Evaluation System, IPAQ: International Physical Activity Questionnaire, LMICs: Low and Middle-Income Countries, VPA: Vigorous Physical Activity, MPA: Moderate Physical Activity, WPA: Walking Physical Activity

\section{Declaration} acknowledgment

The authors would like to express gratitude to participants who helped in filling the google form. 


\section{Funding}

The authors received no financial support for their research, authorship, and/or publication of this article.

\section{Availability of data and materials}

Data will be available by emailing os.adeyemo@oouagoiwoye.edu.ng

\section{Authors' contributions}

Oladotun Sunday Adeyemo conceived the idea, contributed to the design of the questionnaire, wrote the ethical protocol and the manuscripts. Nurudeen Afolabi Sofoluwe contributed to the design of the questionnaire and spearheaded the analysis of the data. Yinusa Olumuyiwa Ganiyu assisted in the design of questionnaires and writing of ethical protocol and significantly contributed to data collection. Odusanya Abidemi Ibrahim contributed to the design of the questionnaires, review of the manuscripts, editing of the manuscripts and data collection. Oyelami, Lukman Oyeyinka contributed in the design of the questionnaire, helped in data collection and analysis, and also in editing of the manuscript. All authors have read and approved the final manuscript.

\section{Ethics approval and consent to participate}

We conducted the research following the Declaration of Helsinki. The ethical protocol was approved by Olabisi Onabanjo University Teaching Hospital Health Research Ethics Committee (OOUTH-HREC) with approval number OOUTH/HREC/354/2020AP. The participants were assured of confidentiality as stated in the google form.

\section{Consent for publication}

Not applicable

\section{Competing interest}

The authors declare that they have no competing interest.

\section{Open Access}

This article is distributed under the terms of the Creative Commons $\begin{array}{llll}\text { Attribution } & 4.0 & \text { International License }\end{array}$ (http://creativecommons.org/licenses/by/4.0/), which permits unrestricted use, distribution, and reproduction in any medium, provided you give appropriate credit to the original author(s) and the source, provide a link to the Creative Commons license, and indicate if changes were made. The Creative Commons Public Domain Dedication waiver (http://creativecommons.org/publicdomain/zero/1.0/) applies to the data made available in this article, unless otherwise stated.

\section{Author details}

${ }^{1}$ Department of Psychology, Faculty of Social Sciences, Olabisi Onabanjo University, Ago-Iwoye, Nigeria. ${ }^{2}$ Department of Cooperative \& Rural Development, Olabisi Onabanjo University, Ago-Iwoye, Nigeria. ${ }^{3}$ Department of Banking \& Finance, Olabisi Onabanjo University, Ago-Iwoye, Nigeria. ${ }^{4}$ Department of Economics, Olabisi Onabanjo University, Ago-Iwoye, Nigeria, ${ }^{5}$ Distance Learning Institute (Economics Unit), University of Lagos, Akoka, Nigeria.

\section{Article Info}

Received: 28 October 2020

Accepted: 10 January 2021

Published: 13 March 2021

\section{References}

1. Qui W, Rutherford S, Mao A, Chu C. The pandemic and its impacts. Health, Culture and Society; 2017:9-10. https://doi.org/10.5195/hcs.2017.221

2. World Health Organization. Coronavirus disease 2019 (COVID19) Situation Report - 32. Available from https://www.who.int/docs/default-source/coronaviruse/situationreports/20200221-sitrep-32-covid-19.pdf.
3. African Arguments. Coronavirus' triple hit in Africa on health, the economy and politics. (The effects of the global pandemic will go far beyond just health concerns). Available from: https://africanarguments.org/2020/03/coronavirus-triple-hit-inafrica-on-health-the-economy-and-politics/

4. Amzat J, Aminu K, Kolo VI, Akinyele AA, Ogundairo JA, Danjibbo MC. Coronavirus outbreak in Nigeria: burden and sociomedical response during the first 100 days. International Journa of Infectious Disease 2020; 98: 218-224. https://doi.org/10.1016/j.ijid.2020.06.067

5. Duncan GE, Avery AR, Edmund S, Tsang S. Perceived change in physical activity levels and mental health during COVID-19: findings among adult twin pairs. PLOS ONE 2020;15(8): e0237695, https://doi.org/10.1371/journal. pone.0237695

6. Chen P, Mao L, Nassis GP, Harmer P, Ainsworth BE, Li F Coronavirus disease (COVID-19): the need to maintain regular physical activity while taking precautions. Journal of Sport and $\begin{array}{lll}\text { Health } & \text { Science2020; } & 9(2): 103104\end{array}$ https://doi.org/10.1016/j.jshs.2020.02.001

7. Lesser IA, Nienhuis CP. The impact of covid-19 on physical activity behaviour and well-being of Canadians. International. Journal of Environmental Research and Public Health 2020;17(11): 3899. https://doi.org/10.3390/ijerph17113899

8. Jakobsson J, Malm C, Furberg C, Ekelund U, Svenssson M. Physical activity during the coronavirus (Covid-19) pandemic: prevention of a decline in metabolic and immunological functions. Frontier in Sports and Active Living: 30 April 2020 https://doi.org/10.3389/fspor.2020.00057.

9. Kang B, Moudon AV, Hurvitz PM, Saelens BE. Increased walking's additive and no substitution effect on total physical activity. Med Sci Sports Exerc 2018; 50(3):468 475. https://doi.org/10.1249/MSS.0000000000001450.

10. Onder M, Rezza G, Brusaferro S. Case-fatality rate and characteristics of patients dying in relation to COVID-19 in Italy. JAMA 2020; https://doi.org/10.1001/jama.2020.4683.

11. Guthold R, Louazani SA, Riley LM, Cowan MJ, Bovet P, Damasceno A, et al. Physical activity in 22 African countries: Results from the World Health Organization STEP wise approach to chronic disease risk factor surveillance. American Journal of Preventive Medicine 2011; 41(1):52-60.

12. Ilesanmi O, Afolabi A. Perception and practices during the covid19 pandemic in an urban community in Nigeria: A cross-sectional study. $\quad$ PeerJ 2020; 8: e10038. http://dx.doi.org/10.7717/peerj.10038

13. Diamond R, Waite F. Physical activity in a pandemic: a new treatment target for psychological therapy. Psychol Psychother 2020;10.1111/papt.12294. https://doi.org/10.1111/papt.12294

14. Stables J. Garmin data reveals how the world is working out during the lockdown: Garmin users are still getting sweaty. Garmin Wearable Tech News, April 11, 2020. Available from: https://www.wareable.com/garmin/garmin-data-lockdown-7940 [Accessed on 04 July 2020]

15. Wenham C, Smith J, Morgan R. COVID-19: the gendered impacts of the outbreak. Lancet 2020;395(10227):846-848. https://doi.org/10.1016/S0140-6736(20)30526-2.

16. Karuc J, Soric M, Radman M, Misigoj-Durakovic M. Moderators of change in physical activity levels during restrictions due to covid-19 pandemic in young urban adults. Sustainability 2020 12(16): 6392. https://doi.org/10.3390/su12166392

17. Sekulic D, Blazevic M, Gilic B, Kvesic I, Zenic N. Prospective analysis of levels and correlates of physical activity during COVID-19 pandemic and imposed rules of social distancing: gender specific study among adolescents from Southern Croatia. Sustainability2020;12: 4072. https://doi.org/10.3390/su12104072

18. Giustino V, Parroco AM, Gennaro A, Musumeci G, Palma A, Battaglia G. Physical activity levels and related energy expenditure during COVID-19 quarantine among the Sicilian active population: a cross-sectional online survey study. Sustainability2020;12(11):4356 https://doi.org/10.3390/su12114356

19. Adegoke BOA, Oyeyemi AL. Physical inactivity in Nigerian young adults: prevalence and socio-demographic correlates. Journal of physical Activity and Health 2011; 8: 1135 -1142.

20. Awotidebe TO, Adedoyin RA, Adegbesan OA, Babalola JF, Olukoju IO, Mbada C, et al. Psychosocial correlates of physical activity participation among Nigerian university students. International Journal of Sports Science 2014; 4(6): 205-211. https://doi.org/10.5923/j.sports.20140406.01 